hilfe und Gynäkologie. An allen Stätten seiner 44 jährigen Wirksamkeit als Lehrer hat er gediegene Geburtshelfer und Aerzte erzogen, denn sein Bestreben ging stets dahin, in seinen klinischen Stunden nicht allein Spezialärzte, sondern ganz besonders Praktiker zu erziehen und ihnen zu zeigen - es sind dies seine eigenen Worte - wie weit sie selbst in ihrem Handeln gehen können und sollen und was, wenn ihr Können nicht mehr ausreicht, die klinische Geburtshilfe leisten kann. In diesem Geiste und zu diesem Zwecke sind auch seine allerorts verbreiteten Lehrbücher entstanden, das Lehrbuch der Frauenkrankheiten, die Operative Geburtshilfe der Praxis und Klinik, die Physiologie und Pathologie des Wochenbetts, das Lehrbuch der Geburtshilfe für Hebammen - Fehlings Verdienste um das Hebammenwesen und den Hebammenunterricht haben nicht allein in Württemberg, sondern ganz allgemein die wohlverdiente Würdigung gefunden.

Abgesehen von seinen Lehrbüchern ist die literarische Produktivität Fehlings auf geburtshilflich-gynäkologischem Gebiete außerordentlich fruchtbar; am besten gibt man sich Rechenschaft davon, wenn man das Archiv für Gynäkologie, das ihn, ebenso wie die Hegarschen Beiträge zur Geburtshilfe und Gynäkologie, zu seinen Herausgebern zählt, durchblättert. Seit dem Jahre 1872 (Bd. 4) sind beinahe in jedem Bande Aufsätze, die seinen Namen tragen, zu finden, so unter anderen die klassischen Studien über die Form des Beckens beim Fötus und Neugeborenen, über die Entstehung der rachitischen Beckenform, über das Wesen und Behandlung der puerperalen Osteomalazie, Porrosche Operation bei Osteomalazie, Kastration bei Osteomalazie usw. Aber auch die modernen Fragen der Grenzgebiete seines Faches: Ehe und Vererbung, die Bestimmung der Frau, Geburten rückgang, Bevölkerungspolitik und Rassenhygiene besohäftigen ihn ernsthaft; Mutterschutz und Säuglingspflege fanden in ihm einen beredten Verteidiger, der praktisch durch die Gründung des Straßburger Säuglingsheims sich hervortat. Ja sogar die Kriegschirurgie verdankt ihm in letzter Zeit Beiträge wie: Kriegschirurgie früher und jetzt, Wundbehandlung bei Kriegsverletzten, Behandlung der Bauchschüsse usw.

Es kann heute Fehling mit Stolz auf seine schöne Laufbahn und ganz besonders auf seine erfolgreiche Arbeit im Elsaß zurückblicken. Umgeben von Aerzten, welche, aus seiner Schule hervorgegangen, die Gründlichkeit seines Unterrichts in der Praxis erprobt und wertzuschätzen gelernt haben, bewundert von unzähligen erkenntlichen Pflegebefohlenen, die ihm Leben und Gesundheit verdanken, verehrt von Freunden und

\section{Zum 70. Geburtstag von Hermann Fehling.}

Als im Frühjahr 1901 W. A. Freund von seinem Lehramte als Professor der Gynäkologie und Direktor der Universitäts-Frauenklinik zurücktrat und von Straßburg Abschied nahm, er, der sich die Gunst und die Liebe der Kollegen, der Aerzteschaft und der Bevölkerung, sowohl der eingewanderten wie der einheimischen, in Sturmeslauf erobert hatte, da schaute mancher, obtohl Prof. Fehling während seiner Baseler Tätigkeit schon im Oberelsaß als Konsiliarius viel begehrt und hochgeschätzt war, doch etwas ängstlich und gedrückt in die Zukunft: wie würde der neue Meister sich in den hiesigen Verhältnissen zurechtfinden, wie würde Fehling nach Freund sich einführen und einbürgern? Die Antwort fällt uns heute leicht!

Die Fehlingsche Schule, wenn auch in etwas von denen seines Vorgängers verschiedenen Bahnen sich bewegend, hat sich hier glänzend bewährt, hat der Fakultät, der Universität, dem Lande hervorragende Dienste geleistet und hat sich die Dankbarkeit speziell der Elsaß-Lothringer errungen; der Name Fehlings ist rasch im Reichslande ein hochgeachteter und wohlklingender geworden. Wenn daher am 14. Juli Hermann Fehling sein siebzigstes Wiegenfest feiert, so werden nicht allein in der Universitäts-Frauenklinik, in welcher er mit unermüdlichem Eifer und Hingabe selbst mitten im Kriege weiter lehrt und schafft, ihn seine Schüler, seine Assistenten, seine Kollegen und Freunde mit wohlverdienten Ehrungen und Beglückwünschungen überraschen, sondern auch im Bethesdahaus, welches infolge der welterschütternden Ereignisse der letzten drei Jahre zum Festungslazarett VII geworden und in welchem er als Chefarzt mit großem Glück chirurgisch tätig ist, werden scine Untergebenen ihrem verehrten Generaloberarzt ihre Huldigungen dar. bringen und diesen Tag festlich begehen.

Diese zwiefache aufreibende Tätigkeit, eine ungewöhnlich rege Arbeitskraft und Arbeitslust erheischend, das Dozieren und Operieren in der Klinik Hand in Hand mit der Leitung eines Lazaretts für schwere Chirurgie, zeugen laut von der Rüstigkeit sowie von der körperlichen und geistigen Frische, welche der Jubilar bis ins hohe Alter hinein sich bewahrt hat. Von früh bis spät ist man gewohnt ihn an der Arbeit zu sehen, seine Studenten, Praktikanten und Assistenten belehrend und anleitend, seine Kranken und $O$ perierten liebevoll pflegend und behandelnd, das Vorbild eines trefflichen, gewissenhaften Lehrers, eines aufopferungsfreudigen Arztes. So hat er gewaltet in Straßburg seit 17 Jahren, nicht anders als in Leipzig als Dozent und erster Assistent von $\mathrm{Cr}$ ed é, in Stuttgart als Direktor der Landeshebammenschule, in Basel und in Halle als Direktor der Frauenklinik und ordentlicher Professor der Geburts-
Bekannten, wird ihm heute von allen Seiten der jubelnde Zuruf entgegenhallen: ad multos annos! 